\title{
Electrochemical Promotion of Propylene Combustion on Ag-based nanostructured catalysts
}

\author{
I. Kalaitzidou, ${ }^{\text {a }}$ T. Cavoue, ${ }^{a}$ A. Boreave, ${ }^{a}$ L. Burel, ${ }^{a}$ F. Gaillard, ${ }^{a}$ M. Rieu,,${ }^{b}$ J.P. \\ Viricelle, ${ }^{\mathrm{b}}$ A. Caravaca, ${ }^{\mathrm{a}}$ and P. Vernoux ${ }^{\mathrm{a}, *}$ \\ ${ }^{a}$ Université de Lyon, Institut de Recherches sur la Catalyse et l'Environnement de Lyon, \\ UMR 5256, CNRS, Université Claude Bernard Lyon 1, 2 avenue A. Einstein, 69626 \\ Villeurbanne, France \\ ${ }^{b}$ École Nationale Supérieure des Mines, SPIN-EMSE, CNRS:UMR5307, LGF, F-42023 \\ Saint-Étienne, France \\ *Corresponding author: (33) (0)472448293, ioanna.kalaitzidou@ircelyon.univ-lyon1.fr
}

\begin{abstract}
Catalytic and electrocatalytic measurements have been carried out in a solid oxide cell for propylene combustion using continuous Ag catalytic films and $\mathrm{Ag}$ nanoparticles dispersed on a mixed ionic electronic conductor film deposited on yttriastabilized zirconia. Similar EPOC behaviors were observed for both samples, indicating that dispersed Ag nanoparticles in LSCF can be electropromoted in a reversible and non-Faradaic manner under lean-burn conditions.
\end{abstract}

Key words: Electrochemical Promotion of Catalysis (EPOC); Propylene Combustion; Ag Catalytic films; dispersed Ag nanoparticles.

1. Introduction: Catalytic combustion as a process used for removal of hydrocarbons from automotive gas exhausts or for energy production has been widely implemented on supported PGM (Platinum Group Metals) based catalysts. Since PGMs are very costly and rare, there is a strong need for an equally effective and less expensive catalyst. The electrochemical promotion of catalysis (EPOC), is a promising concept to in-operando boost catalytic processes in a reversible and controlled manner. The aim of this study was to develop Ag-based electrochemical catalysts for low temperature propylene deep oxidation. The magnitude of the electrochemical promotion has been investigated on continuous screen-printed $\mathrm{Ag}$ films as well as on Ag nanoparticles dispersed into the porosity of LSFC (please add the formula), a mixed ionic electronic conductor (MIEC).

2. Experimental: Nanostructured electrochemical catalysts were prepared by screen-printing and by wet impregnation method. Catalytic and electrocatalytic tests have been carried out in a specific quartz reactor which operated under continuous flowing conditions at atmospheric pressure. The catalytic activity was monitored in a temperature range of 100 to $400{ }^{\circ} \mathrm{C}$ under lean-burn conditions, as encountered in Diesel exhausts. The most active Ag films were also evaluated under closed circuit 
conditions in order to measure the impact of polarization between the silver working electrode and a $\mathrm{Au}$ reference electrode. Both electrodes were exposed to the same atmosphere in a single chamber configuration ${ }^{1}$.

3. Results and discussion: Figure 1 shows typical catalytic activity measurements under current application for a Ag/YSZ sample (a) and a Ag/LSCF/YSZ sample (b) under lean-burn conditions, at $300{ }^{\circ} \mathrm{C}$. The OCV propylene conversion is twice on the dispersed Ag nanoparticles despite a two orders of magnitude lower Ag loading. Furthermore, similar EPOC behaviors were observed for both samples, indicating that dispersed Ag nanoparticles in LSCF can be electropromoted in a reversible and nonFaradaic manner. The predominant impact of current applications is to modify the reactivity of oxygen present on the Ag surface.
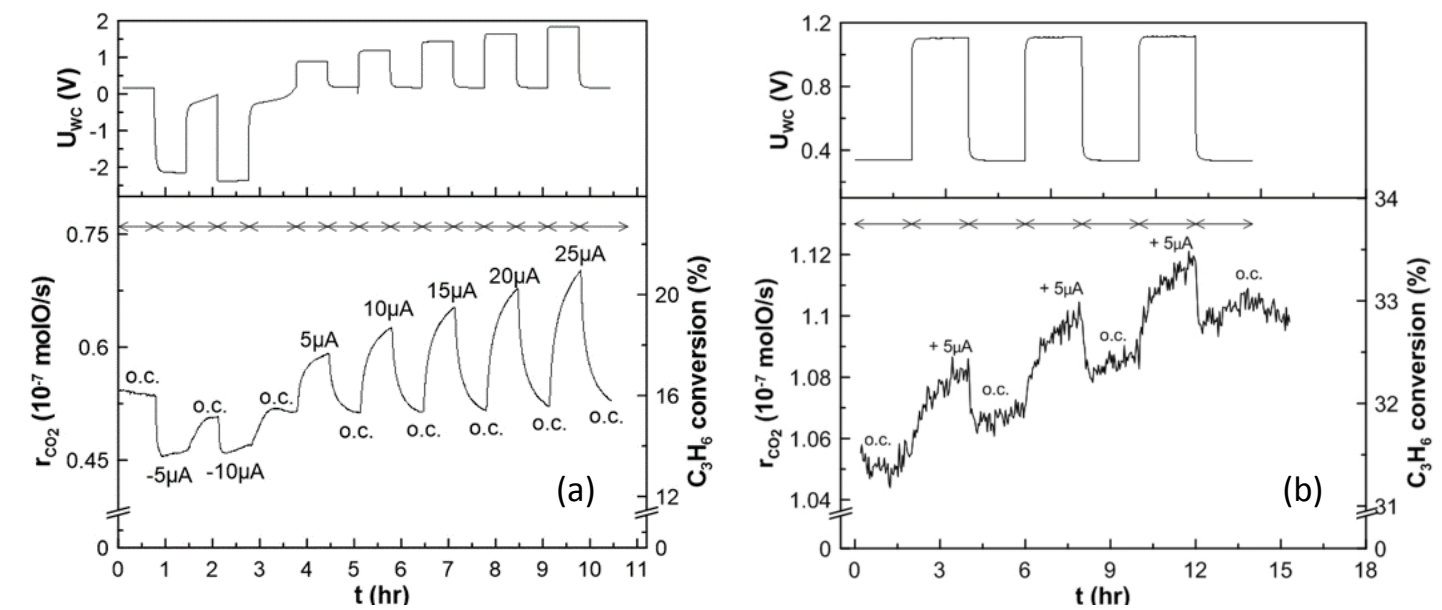

Figure 1. Transient effect of applied currents on $\mathrm{UWC}_{\mathrm{WC}}$ as well as on the catalytic rate of $\mathrm{CO}_{2}$ production and on $\mathrm{C}_{3} \mathrm{H}_{6}$ conversion. $\mathrm{T}=300^{\circ} \mathrm{C}$.

4. Conclusions: This study reports, for the first time, that the catalytic activity for propylene combustion of Ag coatings and Ag nanoparticles supported on LSCF both deposited onto YSZ can be tailored by current applications in a non-Faradaic manner. This study also demonstrates that EPOC can enhance catalytic properties of $\mathrm{Ag}$ nanoparticles dispersed in a MIEC layer for the abatement of propylene in air.

Acknowledgments: This study was performed in the "EPOX" project, funded by the French National Research Agency (ANR), ANR-2015-CE07-0026.

\section{References}

[3] I. Kalaitzidou, T. Cavoue, A. Boreave, L. Burel, F. Gaillard, L. Retailleau-Mevel, E.A. Baranova, M. Rieu, J.P. Viricelle, D. Horwat, P. Vernoux, Cat. Com., 104 (2018) 28-31. 